\title{
POLÍTICAS DE AUDIOVISUAL
}

Laura Bezerra laurabezerra1@gmail.com

Renata Rocha renataptrocha@gmail.com

\section{Políticas para o Cinema O cinema e a conquista do mundo}

Em dezembro de 1895 os irmãos Lumière apresentaram ao público parisiense o cinematógrafo, um aparelho que grava, revela e projeta imagens em movimento e que já no ano seguinte começa a rodar o mundo. Cabe destacar que o advento do cinema é fruto de um longo processo, nada linear. Em 1894, o kinetoscópio de Thomas Alva Edison já exibia imagens em movimento (que, entretanto, não eram projetados, permitindo somente uma recepção individual). Quase dois meses antes dos Lumiére, os irmãos Skadanowski vão exibir imagens em movimento usando um aparelho chamado Bioscop, num show de variedades em Berlim. 
No início, o cinematógrafo era uma atração técnica apresentada em feiras, teatros e outros espaços disponíveis. O cinema dos primórdios era produzido de forma artesanal e familiar. As exibições tampouco eram padronizadas; pode-se mesmo dizer que se tratava de apresentações ao vivo com música e um conferencier que explicava e comentava os filmes. Os exibidores ${ }^{1}$ compravam as fitas e, como donos destas, tinham autonomia para dar uma forma própria ao seu evento, do qual o público participava ativamente: cada programa (com uma combinação de filmes curtos) era único; cada cinema era único, fruto da interação do exibidor com seu público.

Esta brevíssima introdução deve deixar claro que esse primeiro cinema é muito diverso do presente. ${ }^{2}$ E que não há uma linha de desenvolvimento "natural". O modelo que conhecemos se consolida no seio de fortes embates e é marcado pelo entrelaçamento de determinadas condições tecnológicas, econômicas, políticas, artísticas. É deste processo que falaremos aqui.

A partir de 1904, aparecem as primeiras salas de exibição, permitindo, então, uma recepção regular. Aos poucos, o cinema vai se transformando num meio de comunicação de massa e, desde meados dos anos 1910, começa a se consolidar como indústria e como linguagem artística, em paralelo. Visto como indústria ou como arte, o cinema vai adquirir, a partir daí, importância política e será um campo complexo de disputas. Nesta década, acontecem grandes mudanças: há um processo crescente de padronização da produção, agora divida em funções definidas (o produtor, o diretor etc.); nasce o star system, com filmes focados em estrelas com forte potencial de identificação para os espectadores. E a empresa francesa Pathé Frères, em 1908, a maior vendedora obras cinematográficas da época, traz uma novidade que terá consequências significativas: os filmes não são mais vendidos, 
mas sim alugados - e alugados em bloco - o que acaba com a independência dos exibidores.

Nesta mesma época, nos Estados Unidos, um grupo de produtores independentes, lutando contra as tentativas da Motion Pictures Patents Company (MPPC) de monopolizar o mercado mundial, cria um centro de produção em Hollywood, um subúrbio de Los Angeles. Aperfeiçoando os métodos industriais de produção e investindo na construção de uma estrutura vertical que conjuga produção, distribuição e exibição, ${ }^{3}$ este grupo conquista o enorme mercado interno dos EUA e obtém ganhos consideráveis. Até este momento, os países europeus - especialmente França, Dinamarca e Itália - dominam o mercado mundial. Com a I Guerra Mundial, entretanto, há uma queda drástica na produção e distribuição dos filmes da Europa, com exceção da Alemanha e União Soviética. Começa, então, a crescente influência de Hollywood no mundo.

Vão se delineando relações mais fortes entre cinema e Estado. Durante a I Guerra Mundial os governos começam a perceber o valor do cinema para a propaganda. Os Estados Unidos, compreendendo sua importância político-econômica, desenvolve meios para apoiar sua produção cinematográfica no exterior. Por exemplo, é o Export Trade Act promulgado pelo Congresso Americano em 1918, que abre caminho para a formação de oligopólios; a criação da Motion Picture Producers and Distributors Association of America (MPPDA), que reúne grandes estúdios de Hollywood (os “majors"), é um reflexo disso. Esta poderosa associação existe ainda hoje com o nome de Motion Picture Association of America (MPAA) e é formada pelos seis maiores estúdios dos EUA: Disney, Paramount, Sony, Twentieth Century Fox, Universal e Warner. 
Em 1927, o Congresso cria um Departamento de Cinema no Ministério do Comércio: Hollywood é visto como grande exportador do american way of life e, consequentemente, dos produtos estadunidenses. O cinema dos EUA conquista cada vez mais espaço no mercado mundial. Os países europeus reagem com taxações de importações e com um sistema de cotas (que define o número máximo de filmes estrangeiros que podem ser importados a cada ano), mas sem conseguir conter este avanço, que se consolida com o advento do cinema falado.

Em 1947, no mundo polarizado do pós-II Guerra Mundial, é criada a Motion Picture Export Association (MPEA) para defender os interesses dos grandes estúdios e lutar contra barreiras e restrições comerciais; a imbricação com o governo é tal que a MPEA é chamada por seus adversários de "minidepartamento de Estado". ${ }^{4}$ (MATELLART, 2005, p. 69)

Defendendo a livre circulação de mercadorias e o fluxo livre de informações, os governos dos Estados Unidos vêm, desde então, empreendendo enormes esforços para impedir que os governos nacionais implementem políticas de proteção às suas indústrias cinematográficas com lutas travadas não somente nos diferentes países, mas também na Organização Mundial do Comércio (OMC) e na Organização das Nações Unidas para a Educação, a Ciência e a Cultura (Unesco). Temos que deixar claro que esta atuação traz em si uma enorme incoerência: apesar de não ter programas de financiamento direto de filmes, a indústria de cinema dos EUA sempre contou com apoio direto dos governos, o que contradiz a ideia, defendida pelos próprios estadunidenses, do fluxo "livre", ou seja, sem interferências do Estado. Armand Matellart (2005, p. 68) chama atenção para o fato de que o poderio da MPEA foi construído graças a uma "dupla violação da legislação americana. Violação da lei antitruste [...] e violação da 
lei que proíbe as companhias cinematográficas acumularem as funções de produção, distribuição e exploração."

A hegemonia de Hollywood tem como base um controle feroz do sistema mundial de distribuição: $85 \%$ das obras cinematográficas exibidas no mundo saem dos estúdios hollywoodianos - ou seja: no início do século XXI, somente 15\% dos filmes que circulam no mercado mundial não são filmes comerciais estadunidenses. Não é sem motivo que muito se fala em imperialismo cultural. Fato é que o controle do mercado externo é usado por Hollywood para estabelecer os mais diversos padrões - não somente padrões relativos ao conteúdo, estética e formato dos filmes, ou para impor padrões tecnológicos, mas também exportar padrões globais de comportamento e de consumo.

\section{Políticas de cinema no Brasil}

Getúlio Vargas assume o poder em 1930 e inicia profundas reformas no Brasil. Num país com enorme índice de analfabetismo, o cinema nacional é visto por Vargas como um "elemento de aproximação dos habitantes do país". ${ }^{5}$ Com o Decreto no .21 .240 de 1932, primeira lei de cinema do Brasil, o Estado assume uma função regulatória, intervindo em áreas muito diversas do setor. Entre outras coisas, o decreto nacionaliza a censura de filmes, que, até então era de responsabilidade das polícias locais (uma demanda dos produtores); diminui as taxas alfandegárias para a importação de filme virgem (uma forma de fomento à produção) e cria o Departamento de Propaganda e Difusão Cultural (DPDC), que em 1938 seria transformado no famigerado Departamento de Informação e Propaganda (DIP). Seu aspecto mais importante, porém, é instituir o uso do cinema para a formação da 
unidade nacional, com a exibição obrigatória de filmes educativos brasileiros nas salas de cinema antes das obras do circuito comercial - com isso temos a primeira cota de tela (número mínimo de filmes nacionais obrigatórios) do país.

Importante, neste contexto, é o Instituto Nacional de Cinema Educativo (INCE), idealizado por Edgar Roquette-Pinto, que pretendia levar a educação aos lugares mais recônditos do Brasil. Entre 1936 e 1966, o INCE produziu mais de 400 filmes voltados para educação popular e divulgação de ciência, que passavam não somente nas escolas e em eventos culturais, mas também nos cinemas comerciais.

Nos anos seguintes, houve um aumento paulatino da cota de tela ${ }^{6}$ até que, em 1979 - e com isso damos um salto no tempo - o Conselho Nacional de Cinema (Concine) instituiu a mais alta cota que o país já teve: naquele ano as salas, no Brasil, eram obrigadas a exibir filmes nacionais em 140 dias do ano.

As políticas de cinema no Brasil confirmam uma "triste tradição" do país (RUBIM, 2010): os períodos autoritários são marcados por uma forte intervenção do Estado no campo da cultura. A atuação dos governos militares (1964-1985) no cinema será muito bem sucedida no que diz respeito ao controle do mercado interno: em 1979 foram lançados 104 filmes nacionais - em 2007 tivemos 82 lançamentos -; em 1982 as obras brasileiras ocupavam quase $40 \%$ do mercado do país - em 2007: aprox. 12\%. (EARP; SROULEVI$\mathrm{CH}, 2009)$ Este sucesso é fruto de uma política forte e continuada e de uma paradoxal conjunção, na qual cineastas, muitos deles vindos do Cinema Novo, e os militares se unem em torno de um discurso nacionalista de conquista de mercado interno.

Em 1966 é criado o Instituto Nacional de Cinema (INC), que exercerá, nos seus dez anos de atividade, uma importante atividade de regulamentação e fiscalização. O INC vai, por exemplo: 
estabelecer o ingresso padronizado e a obrigatoriedade de borderô e caixas registradoras nos cinemas, o que permite o controle do número de ingressos vendidos (uma reivindicação dos produtores, visando receber sua percentagem da bilheteria); tornar obrigatória a copiagem no Brasil dos filmes estrangeiros destinados à exibição comercial no país (para fortalecer os laboratórios nacionais); instituir o Prêmio INC, mais tarde chamado de "prêmio adicional de bilheteria", um bônus para produtores que houvessem tido bons resultados de bilheteria (esta era uma forma de corrigir as distorções do mercado, fortalecendo o cinema nacional) etc.

Pela primeira vez, o Estado brasileiro vai participar diretamente da produção de filmes, usando, para isso, o imposto sobre a remessa de lucros instituída pela Lei nº 4.131/1962. Aos poucos, porém, o INC vai sendo esvaziado e suas atribuições são assumidas por duas novas instituições: a Empresa Brasileira de Filmes (Embrafilme) e o Conselho Nacional de Cinema (Concine), órgão "de orientação normativa e fiscalização das atividades relativas ao cinema" (Decreto n ${ }^{\circ}$. 77.299/1976). Entre muitas outras coisas o Concine irá estabelecer as condições de comercialização de filmes nacionais e estrangeiros e regulamentar o mercado de vídeos, quando do seu surgimento nos anos 1980. Já a Embrafilme, criada em 1969 para promover o cinema brasileiro no exterior, é reformada e passa, a partir de 1975, a participar diretamente da disputa pelo mercado interno, atuando como produtora e distribuidora de filmes nacionais. A adoção de medidas protecionistas teve um sucesso expressivo, o que fica claro nos números apresentados no parágrafo anterior; a política de cinema do Brasil começa a incomodar as empresas estadunidenses, que através da MPAA, recorrem a pressões diplomáticas, ameaças de retaliação, processos e liminares. (SIMIS, 2008a) 
Com o fim da ditadura militar o Estado se retrai, acreditando que o mercado poderia se autorregular e resolver todas as demandas. No ano de 1992, quando o presidente Collor de Melo extinguiu o Ministério da Cultura e suas vinculadas, inclusive Embrafilme e Concine; não somente o mercado interno fica sem suas instâncias regulatórias, mas também a produção de cinema no Brasil entra em colapso (em 1992 foram lançados apenas três filmes brasileiros, no ano seguinte os filmes nacionais ocupavam $0,05 \%$ do mercado interno). Para fomentar a retomada da produção, Itamar Franco, sucessor de Collor, implementa uma lei de incentivo fiscal específica para o setor, a Lei do Audiovisual, que estimula o investimento privado na atividade. ${ }^{7}$ Esta política audiovisual, praticamente reduzida ao incentivo fiscal e ao fomento à produção, terá continuidade nos dois mandatos de Fernando Henrique Cardoso (FHC). O número de filmes brasileiros lançados vai aumentando paulatinamente (12 filmes em 1995; $30 \mathrm{em}$ 2001), mas, por motivos diversos, o cinema, no Brasil, tornou-se acessível apenas para as elites.

Isto é causado por um conjunto de fatores internos e externos. Com a chegada do vídeo, há, desde meados dos anos 1980, uma queda mundial no número de ingressos vendidos, que é ainda mais acentuada no Brasil por causa da crise econômica e de um aumento exponencial do preço dos ingressos - segundo Earp e Sroulevich (2009), em 1975 foram vendidos mais de 200 milhões de ingressos; em 2007 foram aproximadamente 90 milhões. Uma das consequências é o fechamento dos cinemas de rua e uma reestruturação do sistema de exibição, agora dominada por grupos estrangeiros (como p. ex. o Cinemark, que, em 2009 controlava $18 \%$ das salas de cinema do Brasil), que passam a construir cinemas em shopping centers. Segundo a Ancine temos, em 2009, 2.278 salas de exibição no Brasil (Anos 1970: 3.276 salas). 
No governo Lula, a Secretaria do Audiovisual (SAv), criada no início do governo FHC, foi reestruturada e as políticas setoriais foram articuladas em torno de quatro eixos - produção, difusão, formação e memória e política externa - refletindo uma ampliação do âmbito de atuação da SAv e também uma busca de integração entre os elos da cadeia produtiva do audiovisual. Medidas para a descentralização da produção, fortemente concentrada no eixo Rio-São Paulo, foram implementadas. Além disso, temos duas grandes novidades. Em primeiro lugar, investe-se na democratização da produção e difusão, com programas dirigidos a grupos sociais (não profissionais) até então excluídos das políticas audiovisuais. Segundo: pensa-se no audiovisual como um todo, incluindo a televisão, que tradicionalmente não era contemplada pelas políticas federais de cultura, e os jogos eletrônicos. Observamos um desenvolvimento positivo nas políticas audiovisuais do Brasil. A Agência Nacional de Cinema (Ancine) indica um aumento do número de salas de cinema e de lançamento de filmes brasileiros, ${ }^{8}$ mas uma questão fundamental permanece mal resolvida: o "tripé" planejado no início do governo para formulação e execução da política setorial, formado pela Secretaria do Audiovisual, Ancine e Conselho Superior de Cinema, ${ }^{9}$ não funciona como deveria, havendo queixas de esvaziamento do Conselho e de uma crescente concentração poderes na Ancine.

\section{Políticas para a televisão}

\section{A televisão no mundo ocidental: breve histórico}

Fruto de uma série de pesquisas e descobertas, a televisão - criada entre as décadas de 1920 e 1930 e consolidada apenas após o fim da Segunda Guerra - implica diversas mudanças nos modos de socialização, comportamentos e rotinas da sociedade. 
$\mathrm{Na}$ Europa Ocidental, a maioria dos sistemas televisivos nasce e se configura nos anos 1940 e 1950 seguindo o modelo de "serviço público" diretamente dependente do Estado e de caráter monopolista. Enrique Bustamante (2004) aponta como razões comumente alegadas para tal conformação: a escassez das frequências hertzianas, a importância político-cultural da radiotelevisão, ou a necessidade de preservar esse aparato da pressão comercial, quando não simplesmente a inexistência de grupos privados fortes interessados no setor.

Para além destas questões, frequentemente elencadas, podem ser ressaltadas outras causas "profundas" que contribuem para a opção pela televisão pública no contexto europeu do pós-guerra. A primeira, denominada "econômica", seria a necessidade por parte do Estado de garantir as condições gerais para a reprodução do capital. Já a segunda causa - que o autor classifica como "política", embora também possua características eminentemente culturais -, diz respeito à necessidade de restabelecer o sistema político e a soberania nacional. Em ambos os casos, uma TV centralizada e controlada pelo governo, funcionaria como importante ferramenta, seja para impulsionar o avanço do marketing "fordista", através da ampliação das possibilidades publicitárias e da conformação de um mercado consumidor, seja para promover a restauração do consenso acerca de uma pretendida identidade nacional. ${ }^{10}$

Durante um largo período, tal modelo mantém seus traços essenciais - apesar das constantes inovações tecnológicas e dos acontecimentos sociais, culturais e políticos - o que certamente contribui para detonar a crise que o sistema público de televisão atravessa desde os anos setenta, e para a posta em marcha, na década seguinte, do processo de rerregulação, com a abertura à iniciativa privada. 
O surgimento de um sistema misto - público/privado - traz problemas ainda sem solução para os países da Europa Ocidental, como, por exemplo, a ausência de uma atuação complementar ${ }^{11}$ entre as emissoras. Enquanto os canais privados lutam pela conquista e manutenção da audiência, por vezes em condições desiguais, os públicos enfrentam a diminuição das verbas estatais, a concorrência acirrada e a multiplicação de opções de consumo cultural etc.

O modelo estadunidense, por sua vez, baseia-se desde o seu surgimento no sistema comercial, com grandes empresas no comando das emissoras de televisão. Os rumos tomados pela TV e o acesso ao meio são, obviamente, influenciados por este contexto e, a partir da experiência e estrutura empresarial radiofônica, o oligopólio de três cadeias de TV se constitui nos Estados Unidos, com financiamento exclusivamente comercial:

Em definitivo, o sistema de televisão norte-americano deve ser visto como 'o produto integrado de uma coordenação oligopolística entre as maiores empresas e o governo'[...], sem que a televisão pública, ou PBS, desempenhasse um papel destacado no comportamento desse sistema. Porém, a televisão norte-americana chegou também a ser um paradigma da aplicação das regras do mercado e da televisão concebida como business. ${ }^{12}$ (BUSTAMANTE, 2004. p. 32)

Ou seja, os organismos estatais desempenham um papel decisivo na separação das funções, na proteção de oligopólios frente aos concorrentes e na geração de regras para a produção e programação. Trata-se, portanto, de uma política estatal que contribui sobremaneira para a manutenção do status quo e beneficiamento o mercado. 
Já na América Latina, a dinâmica comercial avança rapidamente e se generaliza a partir dos anos 1950. O processo é avassalador, absorvendo iniciativas públicas ou não lucrativas e instaurando uma quase completa hegemonia privada que só se romperá em algum país pontualmente. E o Brasil não foge a esta regra, conforme veremos a seguir.

\section{A TV no Brasil: políticas de cultura, políticas de comunicação}

A instalação da televisão no Brasil, seguindo o modelo estadunidense de radiodifusão, se dá, não por determinação de um projeto governamental específico, mas a partir do pioneirismo e improvisação do empresário Assis Chateubriand - que já na década de 1940 compra uma emissora da Radio Corporation of America (RCA), nos Estados Unidos.

Anos depois, em 18 de setembro de 1950, é inaugurada, em São Paulo, a primeira televisão da América Latina, a PRF-3, TV Tupi-Difusora. Pertencente ao grupo dos Diários e Emissoras Associados, a emissora inicia suas atividades de maneira precária e improvisada com quadro profissional oriundo, em sua maioria, do rádio. Segundo Simões, Costa e Kehl (1986), já nesta época, os Diários e Emissoras Associados, sob a tutela de Chateaubriand, compunham uma vasta rede de empresas jornalísticas que incluíam jornais impressos, emissoras de rádio e a paradigmática revista semanal O Cruzeiro. No ano seguinte, é inaugurada a TV Tupi Rio, segunda emissora da rede. A programação é produzida localmente e ao vivo. Ao final da década, já existem dez empresas privadas de televisão - inclusive com iniciativas de outros grupos concessionários. ${ }^{13}$ 
Em 1962, mais de uma década depois da inauguração da primeira emissora, é aprovada no congresso nacional a Lei ${ }^{\circ}$. 4.117, que cria o Código Brasileiro de Telecomunicações. No que diz respeito à televisão, dentre outros aspectos, o Código determina que: o serviço de radiodifusão é um serviço público que deve ser executado diretamente pela União ou através de concessão, autorização ou permissão; o prazo de concessão de televisão é de 15 anos, renováveis; a outorga de concessões é uma prerrogativa do Presidente da República; as empresas concessionárias devem ser constituídas exclusivamente de brasileiros natos, bem como seus diretores e gerentes, dentre outros.

Com a instauração do regime militar, a televisão passa a refletir a ideia da função estratégica dos meios de comunicação na divulgação do Estado e das tentativas modernizadoras da sociedade. Apoiada por diversas medidas implantadas pela ditadura, a TV começa a se consolidar como indústria, expandindo o sistema de redes.

Em 1965, ano em que o Brasil se associa ao Sistema Internacional de Satélites (Intelsat), é criada a Empresa Brasileira de Telecomunicações (Embratel). Dois anos depois, a criação do Ministério das Comunicações (Minicom) pelo Decreto-lei n ${ }^{\circ} .200$, centraliza ainda mais o processo decisório no Poder Executivo. ${ }^{14}$ Ainda em 1967, outro Decreto-lei, o n ${ }^{\circ} .236$ torna o Código Brasileiro das Telecomunicações mais repressivo e centralizador, impedindo a divulgação de opiniões contrárias ao governo ditatorial e restringido a propriedade dos meios de comunicação. Configura-se, então, uma política cultural extremamente autoritária, centrada em dois aspectos principais: a concretização da Doutrina de Segurança Nacional e a censura dos meios de comunicação. (RUBIM, A.; RUBIM, L. 2008) 
As emissoras comerciais são sistematicamente beneficiadas pela ação estatal em prol da instituição do projeto de "integração nacional”, que toma corpo. São exemplos deste processo: a instituição do crédito direto ao consumidor em 1968, que facilita a compra de televisore ${ }^{15}$ e o desenvolvimento da rede nacional de micro-ondas da Embratel e do sistema de transmissão via-satélite. O sudeste torna-se o polo irradiador das manifestações culturais, inclusive atraindo artistas de outros estados.

O recrudescimento da ditadura, com o decreto do Ato Institucional $\mathrm{n} .^{\circ} 5$, tem consequências paradoxais na área cultural. Em relação aos movimentos artísticos, a época é de "vazio cultural", apenas contrariado pelo surgimento de estéticas marginais. Já televisão comercial reduz o uso de programas estrangeiros, devido à "preocupação do governo" com seus conteúdos. Ou seja, embora o Estado impulsione a criação de um mercado nacional, este processo de baseia na imposição crescente de um modelo tecnicamente sofisticado e fiel reprodutor da ideologia oficial, beneficiando apenas algumas empresas, com destaque para a Rede Globo. (RUBIM, 2010; BOLAÑO, 1988; ORTIZ, 1988)

Neste aspecto, cabe ressaltar a existência de uma certa esquizofrenia estatal. A ditadura, ao passo que se empenha para realizar a transição do circuito cultural dominante no país - o escolar-universitário - para o midiático, o faz assentada em padrões de mercado, "sem nenhuma interação com as políticas de cultura do Estado. Em suma: institui-se um fosso entre políticas culturais nacionais e o circuito cultural agora dominante no país". (RUBIM, 2010, p. 59)

\section{Autoritarismos comunicacionais e ausências culturais}

Em meados da década de 1970, o fim da ditadura é anunciado pelos militares como uma abertura democrática gradual e segura. 
Em 1985, como consequência deste processo, José Sarney, um civil, torna-se presidente do Brasil, por eleição indireta. Seu governo é marcado pela utilização ostensiva das concessões de televisão como moeda de troca política, principalmente em negociações ligadas ao processo de promulgação da nova Constituição. Entre 1985 e 1988, Sarney outorga 1028 concessões ou permissões de rádio e televisão. À época, isso representa $30 \%$ das concessões feitas no país, desde 1922. (JAMBEIRO, 2002)

Após fortes embates entre entidades ligadas aos trabalhadores da área de comunicação e empresários do setor, durante a Assembleia Constituinte, o texto final do Capítulo da Comunicação Social da Constituição de 1988 se caracteriza por ações como: a extensão da competência da aprovação de concessões ao poder legislativo, além do executivo; a dependência de, no mínimo, dois quintos dos deputados e senadores para reprovar a renovação de uma concessão; o estabelecimento de prazos para permissões e concessões; dentre outras.

Apesar dos avanços obtidos, "a permanência dos princípios básicos da legislação, estabelecidos durante a ditadura, deve-se seguramente ao fato da TV ser um instrumento de poder que o governo civil não quis perder". (JAMBEIRO, 2000, p. 81) E, por sua vez, a maioria dos dispositivos criados - como as determinações que tratam da regionalização de programas; da proibição aos monopólios e oligopólios; e dos direitos dos telespectadores em relação aos serviços prestados pela emissora - permanece aguardando regulamentação.

A atuação na área cultural neste momento e nos governos seguintes (Collor e Itamar) é entremeada de descontinuidades e marcada pela ausência do estado na área cultural, que atinge o ápice no governo de Fernando Henrique Cardoso (1995- 
2002). No entanto, em relação à televisão, a promulgação da Lei no 8.977 de 1995, conhecida com Lei do Cabo, merece relevo, pois possibilitou a existência das emissoras legislativas, universitárias e comunitárias. Parte dessas emissoras passa a transmitir também sinais para antenas parabólicas. O audiovisual, porém, é tratado de forma desintegrada e a TV segue limitada ao âmbito do Ministério das Comunicações de um ponto de vista eminentemente técnico, de modo que:

[...] as áreas de Educação e Cultura pouco tiveram a dizer a respeito, exceto no campo de suas emissoras específicas, de escassa audiência. Assim, quanto ao conteúdo da programação e em especial quanto ao seu compromisso com valores democráticos, o poder público pouco tem efetuado, ficando as poucas iniciativas positivas e as muitas duvidosas ao exclusivo arbítrio das emissoras. (JANINE, 2001, p. 1)

Significa dizer que a ausência de uma política pública efetiva implica na instituição de uma política comunicacional - e, portanto, cultural - regida apenas pelos interesses do mercado. Ainda que não possamos falar em alterações substanciais, esse quadro passa a apresentar novos matizes no momento atual.

\section{Enfrentamentos e limitações: as atuais políticas para o audiovisual}

A partir de 2002, durante as duas gestões de Luiz Inácio Lula da Silva, o Ministério da Cultura (MinC), ao assumir uma noção ampla de cultura, inclui em seu campo de atuação outras modalidades de bens simbólicos, como a televisão, o que representa um importante passo para seu reconhecimento como um aparato cultural. 
Nessa perspectiva, o MinC promove uma série de debates reivindicando a necessária regulamentação do setor audiovisual, seja na frustrada proposta, apresentada em 2004, de transformar a Ancine em Agência Nacional do Cinema e do Audiovisual (Ancinav) ${ }^{16}-$ órgão que abarcaria todo o setor audiovisual -, seja nos debates em torno do projeto de uma lei geral das comunicações. Nesse sentido, outras atuações relevantes são o estímulo às discussões sobre a convergência digital e a atuação no processo de desenvolvimento de um Sistema Brasileiro de Televisão Digital; ${ }^{17}$ bem como a formulação de um projeto de TV pública que resulta na criação de uma emissora nacional do campo público: a TV Brasil. Em relação ao fomento à produção de conteúdo, através de programas e editais de produção e difusão, cabe ressaltar, por fim, que o site do MinC, em abril de 2010, mostra que, entre os catorze programas em andamento na Secretaria do Audiovisual, oito se relacionam com a TV. ${ }^{18}$ Isto revela uma importante mudança de paradigma em sua atuação da durante o Governo Lula. A televisão, que anteriormente não era diretamente contemplada pelas políticas federais de cultura, passa a ter uma posição central nas ações da SAv.

\section{Desafios para uma política audiovisual}

Os meios de comunicação audiovisuais têm uma história muito dinâmica, marcada pelo entrelaçamento de fatores muito diversos como desenvolvimento tecnológico, câmbios estéticos, mudanças políticas, reestruturações de mercado. Visando contribuir para a compreensão e discussão das políticas culturais para o audiovisual, em especial no Brasil, este texto reconstitui a trajetória destas políticas - e em determinados momentos, de suas ausências - 
a partir de dois meios paradigmáticos da área audiovisual: o cinema e a televisão. Embora estes percursos, seus atores e produtos estejam imbricados, optamos por analisá-los separadamente a fim de melhor compreendê-los. É importante frisar que se trata apenas de uma divisão metodológica, visto que os fatos com toda sua complexidade, em geral, não podem ser dissociados.

No Brasil, não apenas o cinema, como já vimos, confirma as "tristes tradições" de ausências em períodos democráticos e florescimento, para o bem e para o mal, nos períodos autoritários das políticas culturais. (RUBIM, 2010) A TV, indiscutivelmente, corrobora com esta afirmação. Por outro lado, desde o surgimento as (muitas) diferenciações se impõem.

Inicialmente, a compreensão do cinema como manifestação artística, o vincula imediatamente à cultura. A televisão, por sua vez, é rotulada como "aparelho ideológico", ou simples vetor de mercantilização, e comumente desconsiderada em seu papel cultural. Desse modo, a atuação do Estado, e mesmo da sociedade civil, junto à televisão se relaciona, de maneira quase automática, a aspectos tecnológicos, mercadológicos (seja no sentido de manutenção do status quo, seja em prol de sua modificação), e políticos.

Mas este é apenas um dos aspectos. A conformação destes dois meios no Brasil, enquanto indústrias culturais, também contribuem para a diferenciação. No caso do cinema, a hegemonia dos Estados Unidos da América no mercado mundial influencia sobremaneira o seu desenvolvimento em outros países. A indústria cinematográfica nacional, por exemplo, não se estabeleceu de forma competitiva, mesmo quando experimentou maior produção. A indústria televisiva, porém, se desenvolveu mundialmente de maneira mais nacionalizada. No país, este meio de comunicação se constitui como indústria de aspecto oligopolístico e altamente rentável, contando com o apoio estratégico do Estado, nos âmbitos do desenvolvimento econômico, da integração nacional e das 
comunicações, em seus aspectos técnicos, embora a finalidade deste apoio sejam, por vezes, notadamente culturais, como a formação de uma identidade nacional, por exemplo.

Tal configuração nos permite trabalhar sob diversas nuances. Em relação à implantação de políticas regulatórias, por exemplo, no caso do cinema, verifica-se uma maior coesão entre empresários, produtores, profissionais e o Estado, no sentido de fortalecer o mercado nacional contra uma "ameaça” externa: o cinema hollywoodiano. Já em relação à TV, há uma imensa desigualdade de forças devido ao desmedido poder de pressão exercido pelos proprietários das grandes emissoras de televisão em relação aos profissionais da área e mesmo ao Estado. Isso se deve não apenas ao desenvolvimento da televisão enquanto indústria, mas também à sua configuração enquanto instrumento de poder e ao fato de que a propriedade dos meios de comunicação, além de concentrada em poucos proprietários, estaria disseminada entre políticos e seus familiares. ${ }^{19}$

Tais constatações podem ser demarcadas de maneira bastante eficaz ao analisarmos o momento atual. As iniciativas do Ministério da Cultura em relação ao audiovisual contaram com a participação dos profissionais do cinema desde sua elaboração e têm adquirido importância fundamental para o desenvolvimento do setor. Por outro lado, a atuação da SAv, embora considere a televisão um tema central em suas políticas, só conseguiu ultrapassar muito pontualmente as fronteiras dos canais públicos. Mesmo nestes casos, como o projeto de criação da TV Brasil, essa atuação se dá de forma conflitante, inclusive no interior do próprio governo. ${ }^{20}$ Outro aspecto a ser superado é a regulamentação da comunicação social. Em que pese a grande defasagem da legislação brasileira, ${ }^{21}$ o tema, devido às polêmicas e resistências que enfrenta, não ultrapassou o status de discussão, a exemplo da Ancinav. 


\section{O desenvolvimento midiático: novíssimo desafio}

Além dos aspectos acima assinalados, outro desafio a ser enfrentado pelas políticas para o audiovisual é a convergência tecnológica. Este processo contemporâneo - no qual os meios de comunicação de massa, as telecomunicações e a internet estão reciprocamente enlaçados - traz mudanças significativas para o audiovisual. "Teles lançam TV digital no celular..." (manchete da Folha de São Paulo em 11/08/2010). "Google lançará internet gratuita por TV nos Estados Unidos ainda este ano” (O Globo, 08/09/2010). Filmes são produzidos para celular e através do celular, que, além disso, são cada vez mais utilizados para acessar internet. Jogos eletrônicos inspiram filmes; filmes são transformados em games. Séries de TV são adaptadas para o cinema e vice-versa. Programas de rádio e televisão podem ser assistidos via internet.

As novas tecnologias trouxeram enormes mudanças para a produção e distribuição de filmes. A produção é mais barata e acessível, abrindo espaço para grupos excluídos do mercado audiovisual; a internet permite uma recepção mundial. Apesar do número de salas de cinema diminuir em todo o mundo, não se pode falar em redução no consumo de filmes; a diferença é que eles são exibidos em diversos suportes: nos cinemas, nas televisões abertas e fechadas, em celulares, em DVDs (oficiais ou piratas). E na internet (de forma autorizada ou não).

O You Tube aparece em 2005 e causa uma espécie de tsunami audiovisual, provocando transformações radicais nas formas de nos relacionarmos com as imagens e modificando as relações de poder estabelecidas. Se, por um lado, observamos a proliferação de imagens privadas e banais, por outro, observamos também uma democratização dos mecanismos de distribuição, que enfraquece os modelos clássicos de cinema, TV e jornalismo, com 
consequências diversas. E de construção da memória: agora é o próprio usuário quem decide que imagens vão circular neste enorme acervo audiovisual coletivo. No You Tube encontramos, lado a lado, preciosos registros de eventos sociopolíticos e imagens de cães fofinhos brincando, músicos amadores desconhecidos e estrelas consagradas, vídeos experimentais de alta qualidade estética, imagens políticas de impacto, obscenidades, o último aniversário da vovó.

Estamos diante da formação de novos paradigmas, no centro de um processo muito dinâmico e não se pode ainda dizer aonde ele nos levará. Fato é que a internet, espaço caracterizado pela a interação entre atores independentes, permite a superação das clássicas relações de poder entre espectador e produtor, profissional e amador - causando imensas dificuldades para a aplicação das antigas leis de direito autoral. Por outro lado, com as novas tecnologias observamos uma fragmentação do público e o surgimento de novas possibilidades comerciais, que já começam a ser exploradas como pay-per-view (pague pelo uso) ou VOD (vídeo sob demanda, com títulos disponíveis para download).

Novos modelos de negócios precisam ser encontrados - e este novo mercado precisa ser regulamentado e seus desequilíbrios, corrigidos. Mas, por quem? Como podem os governos nacionais operar num espaço transnacional que não possui uma legislação aceita internacionalmente? A pirataria, por exemplo, é um tema atual e controverso. Se, por um lado, a proteção aos direitos dos autores é fundamental; por outro lado, muitos aspectos das leis antipirataria protegem, na realidade, as grandes empresas e não os autores. Além disso, o acesso à cultura é também um direito fundamental - no Brasil inclusive garantido pela Constituição Federal de 1988. Estão se configurando novos campos de disputa. Acompanhar o desenvolvimento midiático é, atualmente, o grande desafio para as políticas de audiovisual. 


\section{Notas}

${ }^{1}$ Assim chamados pela atividade desempenhada. No período, ainda não havia a divisão de funções que conhecemos hoje.

${ }^{2}$ Mais sobre este momento instigante do cinema em Gunning (1996).

${ }^{3}$ Posteriormente o domínio conjunto das três áreas, por sua enorme concentração de poder, não será mais permitido nos EUA.

${ }^{4} \mathrm{O}$ autor deixa claro que não se trata apenas de uma política de divisas, a MPEA é uma espécie de peça estratégica na diplomacia americana da Guerra Fria.

5 “O cinema nacional elemento de aproximação dos habitantes do país" é o título de um discurso de Getúlio Vargas.

${ }^{6}$ Em 1939 o Decreto Decreto-lei no 1949 institui a exibição compulsória de um filme nacional de longa-metragem por ano; em 1942 são três filmes por ano.

${ }^{7}$ Uma análise acurada da problemática das leis de incentivo no Brasil pode ser lida em Sarkovas (2005).

${ }^{8}$ Segundo a Ancine foram lançados 84 filmes brasileiros em 2009. A cota de tela varia, atualmente, conforme a quantidade de salas de cada complexo, mas, neste ano, os cinemas do país tiveram que exibir longas nacionais pelo menos durante 28 dias.

${ }^{9}$ Ancine e Conselho Superior de Cinema foram criados em setembro de 2001, através da Medida Provisória 2228, ainda no Governo FHC, mas não saíram do papel até 2003.

${ }^{10} \mathrm{Com}$ exceção da Alemanha. Neste país, por imposição dos aliados - que temiam a reconstituição do espírito nacional alemão - o sistema televisivo foi montado de forma descentralizada e federalizada.

${ }^{11}$ Devido às especificidades de cada modelo (público ou comercial/privado), os papéis a serem desempenhados são distintos. Omar Ricón (2006, p. 16) destaca que a TV pública deveria ser uma alternativa na qual se materialize a diversidade cultural e a promoção da democracia. Já as emissoras comerciais teriam como atribuições: estabelecer referentes culturais e agendas informativas e satisfazer a necessidade de entretenimento da sociedade. A estas últimas, devemos acrescentar ainda a função econômica, que compreenderia o aumento da produção; a formação e expansão de mercados consumidores; a valorização de produtos etc.

12 "En definitiva, el sistema norteamericano de televisión debe ser visto como 'el producto integrado de una coordinación oligopolística entre las mayores compañías y el Gobierno’ (STREETER, 1983), sin que la televisión pública o PBS jugara nunca un rol destacado en el comportamiento de ese sistema. Pero la televisión norteamericana llegó a ser también un paradigma de la aplicación de las reglas del mercado y de la televisión concebida como bussines." 
${ }^{13}$ Para maiores informações sobre este período ver: Simões, Costa e Kehl (1986) e Mattos (2000).

${ }^{14} \mathrm{O}$ Minicom passou a desempenhar as funções que até então eram exercidas por um órgão colegiado e, portanto, de natureza mais democrática: o Conselho Nacional de Telecomunicações (Contel), criado pelo Código Brasileiro de Telecomunicações, de 1962.

${ }^{15} \mathrm{Em} 1968$, as vendas de televisores cresceram $48 \%$ sobre o ano anterior. (MATTOS, 2002, p. 41)

${ }^{16}$ Uma acirrada campanha, empreendida pelos radiodifusores, aliados à grande imprensa tornou patente a dificuldade de se obter consenso em torno da matéria e culminou com o recuo absoluto do governo.

${ }^{17}$ Para mais informações, ver Projeto SBTVD - Questões centrais para uma tomada de decisão: Sugestões do Ministério da Cultura ao Comitê de Desenvolvimento do SBTVD, Disponível em: http://www.cultura.gov.br/upload/ SBTVD_MinC_1143840740.pdf. Acesso em: 10 set. 2008.

${ }^{18}$ São eles: ANIMATV; Brazilian TV Producers; BR Games; Cinema do Brasil; DOCTV; DOCTV IB; DOCTV CPLP; Documenta Brasil; Fomento à Animação; Pontos de Difusão; Programadora Brasil; Rede Olhar Brasil; Revelando os Brasis; TVs e Produção Independente.

${ }^{19} \mathrm{Cf}$. pesquisa Os donos da mídia, realizada pelo Instituto de Estudos e Pesquisas em Comunicação (Epcom). Disponível em: http://www.donosdamidia.com. br/. Acesso em: 19 set. 2010.

${ }^{20}$ Para mais informações ver A Secretaria do Audiovisual/Minc no Governo Lula: políticas de Cultura, políticas de Comunicação da autoria de Moreira, Bezerra e Rocha (2010).

${ }^{21}$ Atualmente a comunicação social no Brasil é regulamentada pela Lei Geral de Comunicações de 1962 e a Constituição de 1988, não teve seus dispositivos, ligados à comunicação social, regulamentados.

\section{Referências}

BOLAÑO, César. Mercado brasileiro de televisão. Aracaju: Universidade Federal de Sergipe, PROEX/CECAC/Programa Editorial, 1988.

BUSTAMANTE, Enrique. La televisión económica: financiación, estrategias y mercados. 2 ed. Barcelona: Gedisa, 2004.

EARP, Fabio Sá; SROULEVICH, Helena. O mercado de cinema no Brasil. In: CALABRE, Lia (Org.). Políticas culturais: reflexões e ações. São Paulo: Itaú Cultural; Rio de Janeiro: Fundação Casa de Rui Barbosa, 2009. p. 181-199. 
GUNNING, Tom. Cinema e história. In: XAVIER, Ismail (Org.). O cinema no século. Rio de Janeiro: Imago, 1996. p. 21-44.

JAMBEIRO, Othon. A TV no Brasil do século XX. Salvador: EDUFBA, 2002. . Regulando a TV: uma visão comparativa no Mercosul. Salvador:

EDUFBA, 2000.

RIBEIRO, Renato Janine. O poder público ausente: a TV nas mãos do mercado. Cadernos de Nosso Tempo, Rio de Janeiro, v. 2, n. 5, p. 207-279, 2001.

LEAL FILHO, Laurindo. A televisão pública brasileira, um vazio histórico. In: ENCONTRO DA COMPÓS, 16., 2007, Curitiba. Anais... Disponível em: http://www.compos.org.br/data/biblioteca_212.pdf. Acesso em: 15 maio 2012.

MARSON, Melina. Cinema e políticas de Estado: da Embrafilme a Ancine. São Paulo: Escrituras, 2009.

MATELLART, Armand. Diversidade cultural e mundialização. São Paulo: Parábola, 2005.

MATTOS, Sérgio. História da televisão brasileira: uma visão econômica, social e política. Petrópolis: Editora Vozes, 2002.

MELEIRO, Alessandra (Org.) Cinema e mercado. São Paulo: Escrituras, 2009. . Cinema e economia política. São Paulo: Escrituras, 2009.

MONACO, James. How to read a film. Oxford: University Press, 1981.

MOREIRA, Fayga; BEZERRA, Laura; ROCHA, Renata. A Secretaria do Audiovisual: políticas de cultura, políticas de comunicação. In: RUBIM, Antonio Albino Canelas. Políticas culturais no Governo Lula. Salvador: EDUFBA, 2010. p. 133-158.

NOWELL-SMITH, Geofrey. The Oxford History of World Cinema. Oxford: University Press, 1996.

ORTIZ, Renato. A moderna tradição brasileira. São Paulo: Brasiliense, 1988.

PALACIO, Manuel. Historia de la televisión en España. Barcelona: Gedisa Editorial, 2001.

RINCÓN, Omar. (Org.). Televisão pública: do consumidor ao cidadão. São Paulo: Friedrich-Ebert-Stiftung, 2002.

RUBIM, Antonio Albino Canelas. Políticas Culturais do Governo Lula/Gil: Desafios e Enfrentamentos. INTERCOM - Revista Brasileira de Ciências da Comunicação. São Paulo, v. 31, n. 1, p. 183-203, jan./jun. 2008. . Políticas culturais no Brasil: itinerários e atualidades. In: BOLAÑO, Cesar et al (Oorg.). Economia da arte e da cultura. São Paulo: Itaú Cultural. p. 51-71. 2010. 
RUBIM, Antonio Albino Canelas; RUBIM, Linda. Televisão e políticas culturais no Brasil Contemporâneo. In: RUBIM, Antonio Albino Canelas; RAMOS, Natália (Org.). Estudos da cultura no Brasil e em Portugal. Salvador: EDUFBA, 2008. p. 183-213.

SARKOVAS, Yacoff. Cultura: o incentivo fiscal no Brasil. Teoria e Debate, n. 62, abr./maio 2005. Disponível em: < http://www.fpabramo.org.br/o-quefazemos/editora/teoria-e-debate/edicoes-anteriores/cultura-o-incentivofiscal-no-brasil >. Acesso em: 15 set. 2008.

SIMIS, Anita. Estado e cinema no Brasil. 2 ed. São Paulo: Annablume: Fapesp: Itaú Cultural, 2008a. $2008 b$.

. Concine - 1976-1990. Políticas Culturais em Revista, v. 1, n. 1, p. 36-55,

.Cinema e política cultural durante a ditadura e a democracia. Disponível em:

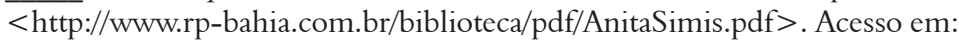
10 dez. 2009.

SIMÕES, Inimá; COSTA, Alcir Henrique da; KEHL, Maria Rita. Um país no ar: história da TV brasileira em três canais. São Paulo: Brasiliense, 1986.

SKLAR, Robert. História social do cinema americano. São Paulo: Cultrix, 1978.

STREETER, T. Policy discourse and broadcast practice: the FCC, the US broadcast networks and the siscours of the market place. Londres: Media Culture \& Society, v. 5, n. 3/4, 1983. 
